\title{
PERAN PEER ASSISTED LEARNING DALAM PEMBELAJARAN PRAKTIKUM ANATOMI DI FAKULTAS KEDOKTERAN UNIVERSITAS ABULYATAMA
}

\author{
Nana Trebna Zulvia ${ }^{1}$, Syarifah Nora Andriaty ${ }^{1}$, Yuni Rahmayanti ${ }^{1}$ \\ ${ }^{1}$ Prodi Pendidikan Dokter, Fakultas Kedokteran, Universitas Abulyatama
}

\begin{abstract}
The Role of Peer Assisted Learning in Study of Anatomy Practicum at The Faculty of Medicine Universitas Abulyatama. There are various of learning methods in faculty of medicine, one of them is Peer Assisted Learning (PAL) which is used in anatomical practice. PAL is a learning method which is using peer tutor as teacher. There is no mutual agreement regarding the curricula content and learning methode of anatomical practice in Indonesia until now. This study is a cross sectional study. The population and sample in this study were all of first year students of faculty of medicine, University of Abulyatama. Data were collected through Clinical Teaching Preference Questionnaires (CTPQ) which measure performance of peer mentor. The total subjects were 87 students. The result showed 1 . Performace of peer mentor divided into five categories: very low $0 \%$, low $6,9 \%$, moderate $23 \%$, high $51,7 \%$, very high $18,4 \%$; and 2 . the anatomical exam results were $31 \%$ passed and $69 \%$ failed. The correlation between peer assisted learning and anatomical practice exam results was $p=$ $0,775$ ( $p>0.05)$. There was no correlation between peer tutor's performance and anatomical practice exam results.
\end{abstract}

Keywords : Learning method, Peer Asissted Learning, Peer tutor

\begin{abstract}
Abstrak : Peran Peer Assisted Learning Dalam Pembelajaran Praktikum Anatomi Di Fakultas Kedokteran Universitas Abulyatama. Metode pembelajaran di fakultas kedokteran bermacam-macam, salah satunya yaitu Peer Assisted Learning (PAL) yang digunakan pada praktikum anatomi. Peer Assisted Learning merupakan pendekatan pembelajaran yang menggunakan peer tutor sebagai pengajar. Sampai sekarang belum ada keseragaman secara nasional dalam kurikulum materi dan model pembelajaran anatomi di Indonesia. Penelitian ini adalah penelitian analitik dengan pendekatan cross sectional. Penelitian ini menggunakan Clinical Teaching Preference Questionnaires (CTPQ). Berdasarkan analisis data diperoleh hasil 1 . Peran peer mentor dibagi menjadi lima kategori yaitu rendah $6.9 \%$, sedang $23 \%$, tinggi $51.7 \%$ dan sangat tinggi $18.4 \%$. Hasil ujian pratikum anatami didapatkan mahasiswa yang ujian praktikum anatomi sebanyak lulus $31 \%$ dan tidak lulus (69\%). Dilakukan uji chi-square didapatkan nilai (P value $=0.775$ ) yang berarti tidak terdapat hubungan antara peran peer assisted learning dengan nilai ujian.
\end{abstract}

Keywords : Metode Pembelajaran, Peer Asissted Learning, Peer tutor

\section{PENDAHULUAN}

Fakultas Kedokteran Universitas Abulyatama menerapkan metode Kurikulum Berbasis Kompetensi (KBK). Proses ini mengacu pada student centered learning yang berarti pembelajaran berpusat kepada mahasiswa bukan teachered centered learning yang berpusat pada pendidik. Student centered learning merupakan metode pembelajaran yang bertujuan agar mahasiswa lebih aktif, yaitu mahasiswa aktif mencari sumber informasi dari buku, diskusi, maupun jurnal (Ardian A, dkk, 2015). Ada beberapa kegiatan pembelajaran yang diikuti mahasiswa pendidikan dokter di Fakultas Kedokteran Universitas Abulyatama yaitu tutorial, keterampilan 
klinik dasar, kuliah, praktikum dan belajar mandiri.

Praktikum anatomi adalah rangkaian kegiatan yang memberikan peserta didik kesempatan untuk mempratikkan ilmu keterampilan dan pengetahuannya. Praktikum anatomi memberikan pengalaman belajar yang bertujuan agar peserta didik mampu memahami, berinteraksi dan mengobservasi terhadap struktur tubuh, bentuk, letak, ukuran, dan hubungan berbagai struktur dari tubuh manusia (Ali A, dkk, 2017).

Metode pembelajaran yang digunakan pada praktikum anatomi di Fakultas Kedokteran Universitas Abulyatama adalah Peer Assisted Learning (PAL). Peer Assisted Learning merupakan pendekatan pembelajaran yang menggunakan peer tutor. Peer tutor sendiri berasal dari mahasiswa yang sudah memenuhi syarat sebagai peer tutor sehingga berkompeten untuk membimbing. PAL banyak digunakan dalam proses belajar mengajar karena dinilai lebih efektif, mahasiswa berbagi informasi dan belajar komunikasi (Suryadi RA, dkk, 2014).

Pelaksanaan PAL dilakukan dengan cara pendampingan oleh asisten dosen selama aktifitas belajar mengajar berlangsung. Mahasiswa akan dibagi menjadi beberapa kelompok dalam 2 sesi, setiap kelompok akan diajarkan langsung oleh asisten dosen. Sebelum melakukan praktikum mahasiswa terlebih dahulu mengikuti pengantar anatomi oleh dosen anatomi, ini berfungsi agar mahasiswa lebih memahami materi yang akan disampaikan pada praktikum tersebut. Praktikum anatomi dilakukan 4 kali dalam 1 bulan, dan penilaian praktikum anatomi di Fakultas Kedokteran Universitas Abulyatama diambil dari nilai kehadiran, nilai post test, nilai tugas, dan nilai tentamen yang akan diakumulasi dengan nilai minimal kelulusan yaitu $\geq 56$. Hal ini mendorong peneliti untuk melihat peran PAL dalam pembelajaran praktikum anatomi pada Fakultas Kedokteran Universitas
Abulyatama.

\section{METODE}

Penelitian ini menggunakan penelitian analitik dengan pendekatan cross sectional, yaitu untuk mengetahui peran Peer Assisted Learning dalam pembelajaran praktikum anatomi. Populasi dalam penelitian ini adalah seluruh mahasiswa Program Studi Pendidikan Dokter di Fakultas Kedokteran Abulyatama angkatan 2019 yang terdata mengikuti praktikum anatomi. Sampel mahasiswa diambil dari populasi dengan teknik total sampling, dengan kriteria sebagai berikut:

Kriteria inklusi dalam penelitian ini antara lain:

a. Mahasiswa Program Studi Pendidikan Dokter angkatan 2019 pada blok tahap awal tiap angkatan di Fakultas Kedokteran Universitas Abulyatama.

b. Mahasiswa yang mengikuti ujian praktikum anatomi pada semester ganjil angkatan 2019.

Kriteria eksklusi dalam penelitian ini antara lain:

a. Mahasiswa yang tidak bersedia menjadi responden

b. Mahasiswa yang menjawab kuesioner dengan tidak lengkap

Dalam penelitian ini peneliti
membagikan kuesioner kepada
responden. Lembar kuesioner berisi
beberapa pertanyaan mengenai
penerapan dan manfaat PAL.
Responden menerima lembar informed
consent sebagai lembar persetujuan
mengikuti penelitian. Kuesioner yang
digunakan adalah Clinical Teaching
Preference Questionnaire (CTPQ). CTPQ
terdiri dari 2 bagian, yaitu bagian
perata (pertanyaan 1-9) mengenai
bagaimana persepsi mahasiswa
mengenai penerapan PAL dan bagian
kedua (pertanyaan nomor 10 )
mengenai manfaat metode PAL.
Pertanyaan nomor $1-10$
diberikan poin berdasarkan pilihan
jawaban, yaitu: 4
a. Sangat setuju = 5

a. Sangat setuju $=5$ 
b. Setuju $=4$

c. Cukup setuju $=3$

d. Tidak setuju $=2$

e. Sangat tidak setuju $=1$

Kemudian peneliti melakukan pengumpulan data sekunder, yaitu hasil ujian praktikum anatomi di Fakultas Kedokteran Universitas Abulyatama yang sudah di akumulasi. Akumulai nilai anatomi diambil dari penilaian kehadiran $(10 \%)$, nilai pretest $(15 \%)$, nilai tugas $(15 \%)$, dan nilai tentamen $(60 \%)$.

Selanjutnya hasil kuesioner akan diujikan dengan data sekunder untuk mengetahui peran PAL terhadap hasil ujian praktikum anatomi di Fakultas Kedokteran Universitas Abulyatama.

\section{HASIL}

\section{Analisis Univariat}

a. Peer Assisted Learning(PAL)

\section{Tabel 4.1 Kategorisasi Peer Assisted Learning}

\begin{tabular}{ccc}
\hline PAL & $\begin{array}{c}\text { Frekuensi } \\
(\mathbf{n})\end{array}$ & $\begin{array}{c}\text { Persentase } \\
(\mathbf{\%})\end{array}$ \\
\hline Sangat Rendah & $\mathbf{0}$ & $\mathbf{0 , 0}$ \\
Rendah & $\mathbf{6}$ & $\mathbf{6 , 9}$ \\
Sedang & $\mathbf{2 0}$ & $\mathbf{2 3 , 0}$ \\
Tinggi & $\mathbf{4 5}$ & $\mathbf{5 1 , 7}$ \\
Sangat tinggi & $\mathbf{1 6}$ & $\mathbf{1 8 , 4}$ \\
\hline Total & $\mathbf{8 7}$ & $\mathbf{1 0 0 , 0}$ \\
\hline
\end{tabular}

Berdasarkan tabel di atas dapat dilihat bahwa responden yang menyatakan peran Peer Assisted Learning (PAL) sangat rendah sebanyak 0 orang $(0 \%)$, tingkat Peer Assisted Learning (PAL) rendah sebanyak 6 orang $(6,9 \%)$, tingkat Peer Assisted
Learning (PAL) sedang sebanyak 20 orang $(23,0 \%)$, tingkat Peer Assisted Learning (PAL) tinggi sebanyak 45 orang $(51,7 \%)$, dan tingkat Peer Assisted Learning (PAL) sangat tinggi sebanyak 16 orang $(18,4 \%)$.

a. Pertanyaan Kuesioner

Tabel 4.2 Kategori Pertanyaan Kuesioner

\begin{tabular}{|c|c|c|c|c|c|c|c|c|c|c|}
\hline \multirow[t]{2}{*}{ Kategori } & \multicolumn{2}{|c|}{$\begin{array}{l}\text { Sangat } \\
\text { Setuju }\end{array}$} & \multicolumn{2}{|c|}{ Setuju } & \multicolumn{2}{|c|}{$\begin{array}{l}\text { Cukup } \\
\text { Setuju }\end{array}$} & \multicolumn{2}{|c|}{$\begin{array}{l}\text { Tidak } \\
\text { Setuju }\end{array}$} & \multicolumn{2}{|c|}{$\begin{array}{l}\text { Sangat } \\
\text { Tidak } \\
\text { Setuju }\end{array}$} \\
\hline & $\mathrm{n}$ & $\%$ & $\mathrm{n}$ & $\%$ & $\mathrm{n}$ & $\%$ & $\mathrm{~N}$ & $\%$ & $\mathrm{n}$ & $\%$ \\
\hline \multicolumn{11}{|l|}{ Peer tutor } \\
\hline $\begin{array}{l}\text { Kenyamanan } \\
\text { belajar }\end{array}$ & 6 & 6,9 & 45 & 51,72 & 20 & 22,99 & 16 & 18,39 & 0 & 0 \\
\hline $\begin{array}{l}\text { Interaksi dan } \\
\text { kerjasama }\end{array}$ & 15 & 17,24 & 42 & 48,28 & 20 & 22,99 & 10 & 11,49 & 0 & 0 \\
\hline $\begin{array}{l}\text { Hubungan } \\
\text { komunikasi }\end{array}$ & 14 & 16,09 & 50 & 57,47 & 17 & 19,54 & 6 & 6,9 & 0 & 0 \\
\hline $\begin{array}{l}\text { Membantu } \\
\text { pembelajaran }\end{array}$ & 22 & 25,29 & 45 & 51,72 & 15 & 17,24 & 5 & 5,75 & 0 & 0 \\
\hline $\begin{array}{l}\text { Kepercayaan diri } \\
\text { dan kemandirian }\end{array}$ & 4 & 4,6 & 44 & 50,57 & 30 & 34,48 & 9 & 10,34 & $\mathbf{0}$ & $\mathbf{0}$ \\
\hline Umpan balik yang & 7 & 8,05 & 42 & 48,28 & 25 & 28,74 & 12 & 13,79 & 1 & 1,15 \\
\hline
\end{tabular}


diterima

\begin{tabular}{|c|c|c|c|c|c|c|c|c|c|c|}
\hline $\begin{array}{l}\text { Kemampuan } \\
\text { menjawab soal }\end{array}$ & 13 & 14,94 & 45 & 51,72 & 20 & 22,99 & 9 & 10,34 & $\mathbf{0}$ & $\mathbf{0}$ \\
\hline $\begin{array}{l}\text { Teori dan keilmuan } \\
\text { anatomi }\end{array}$ & 12 & 13,79 & 42 & 48,28 & 22 & 25,29 & 11 & 12,64 & $\mathbf{0}$ & $\mathbf{0}$ \\
\hline Bantuan belajar & 4 & 4,6 & 22 & 25,29 & 34 & 39,08 & 27 & 31,03 & $\mathbf{0}$ & $\mathbf{0}$ \\
\hline $\begin{array}{l}\text { Tanggung jawab } \\
\text { terhadap diri } \\
\text { sendiri }\end{array}$ & 12 & 13,79 & 48 & 55,17 & 24 & 27,59 & 1 & 1,15 & 2 & 2,3 \\
\hline
\end{tabular}

Berdasarkan tabel di atas dapat dilihat bahwa peran peer tutor sangat membantu dalam pembelajaran karena mempermudah komunikasi pada saat praktikum anatomi, namun tidak

c. Hasil Ujian Praktikum Anatomi memberikan kenyamanan pada saat pembelajaran praktikum. Sebanyak (51.72 \%) mahasiswa setuju bahwa dosen lebih berperan dalam menyampaikan keilmuannya.

Tabel 4.3 Distribusi Kategori Hasil Ujian Pratikum Anatomi

\begin{tabular}{ccc}
\hline $\begin{array}{c}\text { Tingkat } \\
\text { Pendidikan }\end{array}$ & Frekuensi (n) & Persentase (\%) \\
\hline Lulus & $\mathbf{2 7}$ & $\mathbf{3 1 , 0}$ \\
Tidak Lulus & $\mathbf{6 0}$ & $\mathbf{6 9 , 0}$ \\
\hline Total & $\mathbf{8 7}$ & $\mathbf{1 0 0 , 0}$ \\
\hline
\end{tabular}

Berdasarkan tabel di atas dapat dilihat bahwa responden yang lulus ujian praktikum anatomi sebanyak 27 orang $(31,0 \%)$ dan responden yang tidak lulus ujian praktikum anatomi sebanyak 60 orang $(69,0 \%)$.

\section{Analisis Bivariat}

a. Peran Peer Assisted Learning (PAL) terhadap Hasil Ujian Praktikum Anatomi.

\section{Tabel 4.4 Peran Peer Assisted Learning (PAL) terhadap Hasil Ujian Anatomi}

\begin{tabular}{|c|c|c|c|c|c|c|c|}
\hline \multirow{3}{*}{ PAL } & \multicolumn{4}{|c|}{ Hasil Ujian } & \multicolumn{2}{|c|}{ Total } & \multirow[t]{2}{*}{$\mathbf{P}$} \\
\hline & \multicolumn{2}{|c|}{ Lulus } & \multicolumn{2}{|c|}{$\begin{array}{l}\text { Tidak } \\
\text { Lulus }\end{array}$} & & & \\
\hline & $\mathrm{N}$ & $\%$ & $\mathrm{~N}$ & $\%$ & $\mathrm{~N}$ & $\%$ & \\
\hline $\begin{array}{l}\text { Sangat } \\
\text { Rendah }\end{array}$ & $\mathbf{0}$ & 0,0 & $\mathbf{0}$ & 0,0 & $\mathbf{0}$ & 0,0 & \\
\hline Rendah & 1 & 16,7 & 5 & 83,3 & 6 & 100,0 & \\
\hline Sedang & 7 & 35,0 & 13 & 65,0 & 20 & 100,0 & 0775 \\
\hline Tinggi & 15 & 33,3 & 30 & 66,7 & 45 & 100,0 & כות \\
\hline $\begin{array}{l}\text { Sangat } \\
\text { Tinggi }\end{array}$ & 4 & 25,0 & 12 & 75,0 & 16 & 100,0 & \\
\hline Total & 27 & 31,0 & 60 & 69,0 & 87 & 100,0 & \\
\hline
\end{tabular}

Berdasarkan tabel di atas dapat menyatakan kemampuan Peer Assisted dilihat bahwa responden yang Learning (PAL) sangat rendah dan lulus 
ujian sebanyak 0 orang $(0,0 \%)$ serta yang tidak lulus ujian juga sebanyak 0 orang $(0,0 \%)$ karena tidak ada responden yang menyatakan kemampuan Peer Assisted Learning (PAL) nya sangat rendah.

Responden yang menyatakan kemampuan Peer Assisted Learning (PAL) rendah yang lulus ujian sebanyak 1 orang $(16,7 \%)$ sedangkan yang tidak lulus 5 orang $(83.3 \%)$. Responden yang menyatakan kemampuan Peer Assisted Learning (PAL) sedang yang lulus ujian sebanyak 7 orang (35\%) sedangkan yang tidak lulus 13 orang (65\%). Responden yang menyatakan kemampuan Peer Assisted Learning (PAL) tinggi yang lulus ujian sebanyak 15 orang $(33.3 \%)$ sedangkan yang tidak lulus ujian 30 orang (66.7\%).

Responden yang menyatakan kemampuan Peer Assisted Learning (PAL) sangat tinggi yang lulus ujian sebanyak 4 orang (25\%) sedangkan responden yang tidak lulus 12 orang $(75 \%)$. Analisis bivariat mengetahui peran Peer Assisted Learning (PAL) terhadap hasil ujian anatomi dilakukan tabulasi silang (analisis chi square) dan secara statistik menunjukkan tidak terdapat peran Peer Assisted Learning (PAL) terhadap hasil ujian anatomi, dengan nilai $P=0,775(P>0,05)$.

\section{PEMBAHASAN}

Penelitian ini bertujuan untuk mengetahui peran PAL terhadap hasil ujian praktikum anatomi di Fakultas Kedokteran Universitas Abulyatama. Berdasarkan dari hasil pengujian SPSS, nilai $\mathrm{P}$ membuktikan tidak terdapat peran Peer Assisted Learning (PAL) terhadap hasil ujian anatomi. Hal ini ditandai dari hasil uji analisis bivariat yang telah dilakukan sehingga diperoleh hasil uji Chi-Square dengan nilai P-Value adalah 0,775.

Penelitian ini sejalan dengan penelitian Irvan Miftahul dengan judul hubungan persepsi mahasiswa tentang peer assisted learning (PAL) pratikum anatomi dengan hasil ujian pratikum anatomi Fakultas Kedokteran Universitas Lampung, yang memiliki hasil tidak terdapat hubungan antara persepsi mahasiswa tentang peer assisted learning dengan hasil ujian pratikum anatomi Fakultas Kedokteran Universitas Lampung (Arif IM. 2018).

Peer Assisted Learning (PAL) merupakan suatu metode pembelajaran dengan cara berdiskusi dengan aktif dan kooperatif serta tetap mengacu kepada target kurikulum. Pada penelitian ini digunakan PAL yang bertindak sebagai tutor adalah mahasiswa angkatan 2017 dan yang berperan sebagai pembelajar adalah mahasiswa angkatan 2019.

Peer tutor sangat membantu dalam pembelajaran karena mahasiswa lebih mudah melakukan komunikasi pada saat praktikum anatomi, namun tidak memberikan kenyamanan pada saat pembelajaran praktikum. Sebanyak (51.72 \%) mahasiswa setuju bahwa dosen lebih berperan dalam menyampaikan keilmuannya.

Penelitian dari Dian Puspita dengan judul peran rekan mahasiswa senior dalam transisi mahasiswa pendidikan klinis tahun 2018 mendukung dari fakta yang ada di laboratorium anatomi Fakultas Kedokteran Universitas Abulyatama karena menunjukan bahwa terdapat peran senior dalam peningkatan akademisi seorang mahasiswa dibawahnya karena dapat membantu dan mendukung dalam kegiatan pembelajaran (Ardian A, dkk, 2015).

Penelitian dari Saharnauli dan Verawaty dengan judul metode pembelajaran Peer Assisted Learning pada pratikum anatomi tahun 2015 menunjukan sekitar $90 \%$ setuju bahwa metode PAL dapat meningkatkan pemahaman tentang ilmu yang dipelajari (Andriaty SN, dkk ,2016). Pada penelitian dari Saharnauli dan Verawaty juga menunjukan hasil analisa dengan menggunakan $u j i \mathrm{~T}$ berpasangan dan uji Wilcoxon samasama menunjukan $\mathrm{P}>0.05$ yang berarti metode pembelajaran pratikum anatomi tidak memberikan perbedaan yang begitu bermakna pada pencapai hasil ujian akadamik Mahasiswa (Adekoya YM, dkk, 2011). 
Pada laboratorium anatomi UNAYA pencapaian nilai ujian tidak memuaskan, hal itu dapat disebabkan sebagian besar mahasiswa FK UNAYA tidak aktif dalam proses pembelajaran, kurangnya rasa tanggung jawab, dan kemandirian (Andriaty SN, dkk, 2016).

Namun kelulusan ujian bukan ditentukan oleh peran peer tutor saja. Kelulusan ujian dapat dipengaruhi oleh beberapa faktor, baik faktor internal (motivasi, kesehatan fisik, kemampuan kognitif), maupun faktor eksternal (materi pembelajaran, lingkungan belajar, sarana prasarana, sumber daya manusia). (Azwar S.,2018 dan Saharnauli J, dkk, 2015). Faktor tersebut sejalan dengan penelitian Cut Khairunnisa dengan judul faktor yang mempengaruhi kelulusan mahasiswa Program Studi Kedokteran Universitas Malikussaleh, yang menunjukkan bahwa tingkat keberhasilan akademik mahasiswa dapat dipengaruhi oleh tingkat kecerdasan intelijesia dan dapat diukur dari hasil ujian (Khairunnisa C, 2015).

\section{KESIMPULAN}

Berdasarkan penelitian yang telah dilakukan di laboratorium anatomi pada Program Studi Pendidikan Dokter di Fakultas Kedokteran Universitas Abulyatama mulai dari bulan Desember - Juni 2019, diperoleh bahwa:

a) Hasil yang didapatkan peran Peer Assisted Learning tergolong dalam kategori tinggi.

b) Jumlah mahasiswa yang lulus ujian praktikum anatomi lebih besar dari pada mahasiswa yang tidak lulus.

c) Peran Peer Assisted Learning (PAL) terhadap hasil ujian pratikum laboratorium anatomi menunjukkan tidak terdapat peran PAL yang signifikan terhadap hasil ujian anatomi.

\section{DAFTAR PUSTAKA}

Ardian A, Munadi S. (2015). Pengaruh Strategi Pembelajaran StudentCentered Learning dan
Kemampuan Spasial Terhadap Kreativitas Mahasiswa. Jurnal Pendidikan Teknologi dan Kejuruan 22(4):455-66. Diunduh pada tanggal 1 April 2020 dari https://journal.uny.ac.id/index.p hp/jptk/article/view/7843

Arif IM. (2018). "Hubungan Persepsi Mahasiswa Tentang Peer Assisted Learning (PAL) Pratikum Anatomi Dengan Hasil Ujian Anatomi Fakultas Kedokteran Universitas Lampung". [Skripsi]. Lampung: Universitas Lampung.

Adekoya YM, Ed M, Olatoye RA, Ph D. (2011). Effect of Demonstration, Peer-Tutoring, and Lecture Teaching Strategies on Senior Secondary School Students Achievement in an Aspect of Agricultural Science. Pacific Journal Science Technology 12(1):320-32. Diunduh pada tanggal 17 Juni 2020dari https://www.researchgate.net/pr ofile/Olatoye_Ademola/publicatio n/265811937_Effect_of_Demonst ration_Peer-

Tutoring_and_Lecture_Teaching_ Strategies_on_Senior_Secondary _School_Students'_Achievement _in_an_Aspect_of_Agricultural_S cience/links/55bbfbfb08aed621de 0dc76f.pdf

Ali A. (2017). Analisis Pelaksanaan Praktikum Anatomi Fisiologi Tumbuhan Jurusan Pendidikan Biologi Semester Genap Tahun Akademik 2016/2017. Jurnal Biotek 5:144-54. Diunduh pada tanggal 17 April 2020 dari http://journal.uinalauddin.ac.id/index.php/biotek/a rticle/view/3454

Azwar S. (2018). Penyusunan Skala Psikologi. II. Yogyakarta: Pustaka Pelajar.

Andriaty SN, Findyartini A, Werdhani RA. (2016). Studi Eksplorasi Kemungkinan Penyebab Kegagalan Mahasiswa Dalam Uji kompetensi Dokter Indonesia, Studi Kasus Di Fakultas Kedokteran Universitas Abulyatana. Jurnal Serambi 
3(2):1-12. Diunduh pada tanggal 27 Juni 2020dari http://ojs.serambimekkah.ac.id/s erambi-ptk/article/view/296

Khairunnisa C. (2015). Faktor yang Mempengaruhi Kelulusan Mahasiswa Program Studi Kedokteran Universitas Malikussaleh. Jurnal Samudera 9(1):1-22.

Saharnauli J, Verawaty S. (2015). Metode Pembelajaran Peer Assisted Learning Pada Pratikum Anatomi. Jurnal Pendidikan Kedokteran Indonesia 4(2):5864 . Diunduh pada tanggal 27 Juni 2020

dari https://dev.jurnal.ugm.ac.id/jpki /article/view/25282

Suryadi RA, Rukmini E. (2014). Perspektif Mahasiswa Terhadap Visualized Peer-Assisted Stundent ' Fakultas Kedokteran Universitas Katolik Indonesia. Damianus Journal Medicine 13(2):95-109. Diunduh pada tanggal 1 April 2020 dari http://ojs.atmajaya.ac.id/index.p hp/duludamianus/article/view/23 8

Unsta NLR. (2017). Aplikasi Tutorial Pembelajaran Anatomi Tubuh Manusia Menggunakan Web. 